\title{
On Implementation Possibilities of High-Voltage IGBTs in Resonant Converters
}

\author{
Andrei Blinov and Dmitri Vinnikov \\ Tallinn University of Technology, Ehitajate tee 5, 19086 Tallinn, Estonia
}

\begin{abstract}
The conventional hard switching half-bridge topology used as a rolling stock auxiliary power supply unit has limited switching frequency due to high power losses in semiconductors. The study analyses LLC and LCC topologies in attempt to improve the performance of the converter and presents a simulation of the operation and an estimation of power losses.
\end{abstract}

Keywords: resonant converter, half bridge, power losses.

\section{Introduction}

Along with the development of $6.5 \mathrm{kV}$ IGBT modules, complex applications managed by series connection of numerous lower voltage semiconductors could be simplified by replacing them with a single $6.5 \mathrm{kV}$ module, which would enable simple and reliable two-level half-bridge (HB) voltage-source inverter (VSI) topologies to be implemented for the rolling stock auxiliary power units.

This research focuses on an experimental half-bridge converter recently developed at Tallinn University of Technology. This converter is based on two Infineon $200 \mathrm{~A}$ $6.5 \mathrm{kV}$ IGBT modules (FZ200R65KF1). Investigations have shown that the experimental converter is capable of providing required performance within the whole range of rolling stock supply voltage of $2.2 \ldots 4.0 \mathrm{kV}$ and a wide power range $10 \ldots 50 \mathrm{~kW}[1]$. The converter consists of primary and secondary parts galvanically isolated by the high frequency transformer. The primary part is a square-wave twolevel half-bridge PWM inverter and the secondary part consists of a full-bridge rectifier and an LC filter. Such converters (Fig. 1a) are very simple in control and protection, have reduced component count and provide good reliability.

Main concerns of this topology relate to parasitic oscillations after IGBT turn-off (Fig. 1b) [2], high power losses in semiconductors due to hard switching and consequently, limited switching frequency (around $2 \mathrm{kHz}$ ) because of thermal issues. This imposes increased requirements on the passive components of the converter and associated cooling system. As a result this leads to increased price and reduced power density of the converter. Several ways exist of how to improve the switching process of semiconductor switches in the $\mathrm{HB}$ inverters, which can be classified as asymmetrical, auxiliary switch, and resonant converters [3].

This however, requires increased number of components including controlled switches. Due to increased complexity the reliability is expected to be decreasing. 
Investigations of $6.5 \mathrm{kV}$ IGBTs operating in resonant topologies report significant increase in efficiency $[6,7]$, however, the transistors were operating in both zero voltage switching (ZVS) and quasi- zero current switching (ZCS) mode.

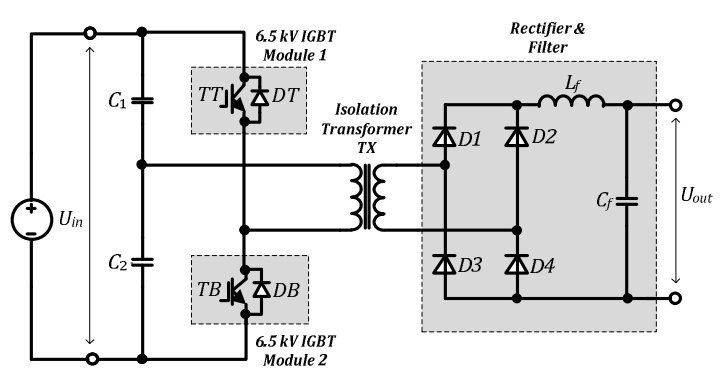

(a)

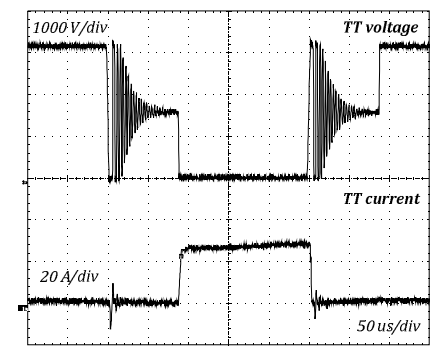

(b)

Fig. 1. Hard-switched high-voltage half-bridge converter topology (a) and measured IGBT voltage and current waveforms (b)

This mode of operation is hard to achieve with wide input voltage and load variations. The following investigation focuses on the HB resonant converters based on two $6.5 \mathrm{kV}$ IGBT modules that require minimum modifications to the hardswitched topology.

\section{Contribution to Value Creation}

Modern high-voltage power electronic applications relate to several fields, such as industrial electrical drives and traction as well as equipment for power generation, transmission and distribution. There are trade-offs between size, complexity, reliability, cost and many other parameters of the system. Evaluation of these factors is critical to achieve an optimum valuable design. This is often impossible without taking into account the most innovative technology achievements or without applying the available solutions to particular needs. This article investigates the ways of optimisation of the experimental converter in an attempt to create a more valuable and innovative system.

\section{Resonant Converter Types}

Resonant converters are an attractive alternative to traditional hard-switched ones because of reduced switching losses and the EMI due to the sinusoidal behaviour of the resonant circuit. Such converters (Fig. 2) could operate at high frequencies to reduce the size of their reactive components. These converters generally feature the second or the third order resonant tank circuit, i.e. the storage tank consists of two or three energy storage elements [8]. Resonant tanks can be divided into three groups as series (Fig. 2a), parallel (Fig. 2b) and series-parallel. In turn, converters with seriesparallel resonant tanks could be classified as LCC, and LLC (Figs. $2 \mathrm{c}$ and $2 \mathrm{~d}$, respectively). In resonant converters regulation of output parameters is performed by varying the IGBT switching frequency around the resonance frequency of the converter [3]. 


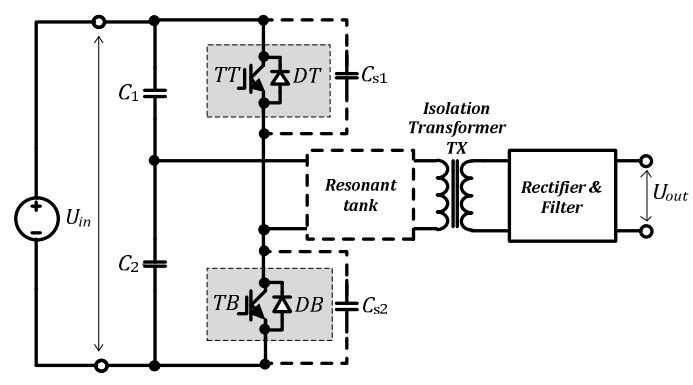

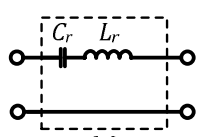

(a)

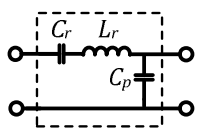

(c)

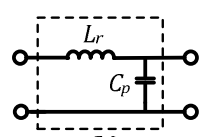

(b)

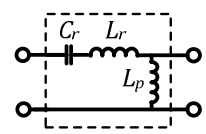

(d)

Fig. 2. Generalised resonant converter topology and different resonant tanks

A major advantage of a series-resonant converter is that the current in the power devices decreases with a decrease in the load, leading to higher efficiency. However, there are difficulties in regulating the output voltage at light load operation [9, 10]. Since the studied converter must operate with wide load variations, this topology is not considered suitable. In contrast to the series-resonant converter, the parallelresonant converter can regulate the output voltage at no load by running at a frequency above resonance. On the other hand, such converters have higher device current that is relatively independent of the load. This leads to high conduction losses in semiconductor and reactive components, decreasing the efficiency, especially at light loads.

\section{$4 \quad$ LLC Resonant Converter}

LLC resonant converters introduce several advantages over other resonant converters. These converters require a relatively narrow variation of switching frequency to control the output voltage; can operate with a wide load range and ZVS could be achieved over the entire operating range. Moreover, the transformer leakage and magnetizing inductances can be utilised as the resonant elements of the power stage and, thus, reduce the overall part count. In addition, the series resonant capacitor also provides DC blocking, favourable for an isolation transformer in the half-bridge configuration. The LLC converter has two resonant frequencies: $L_{r}$ and $C_{r}$ determine the higher resonant frequency, while lower resonant frequency is determined by $C_{r}$ and the series inductance of $L_{p}$ and $L_{r}$. The characteristics of the converter are dependent on the $L_{r} / L_{p}$ inductor ratio. As $L_{r}$ is reduced, the lower frequency needed at low voltage input decreases. In this case variations in the switching frequency within the operating range are increased, resulting in a complicated passive component design. On the other hand, larger $L_{r}$ will make the IGBT turn-off current higher, which increases switching losses. Two resonant frequencies, $f_{r 1(L L C)}$ and $f_{r 2(L L C)}$ are defined as follows [5]: 


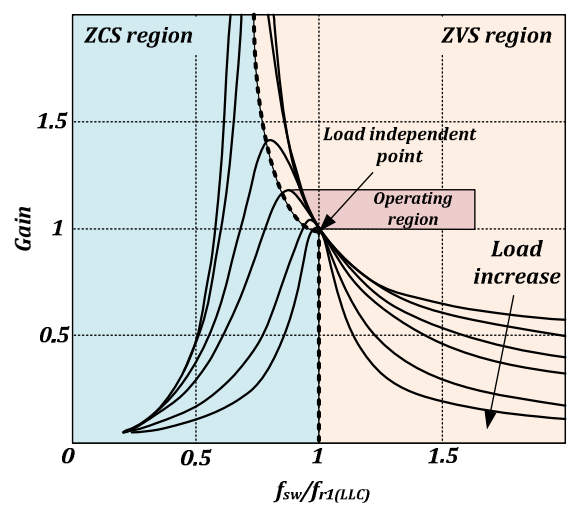

(a)

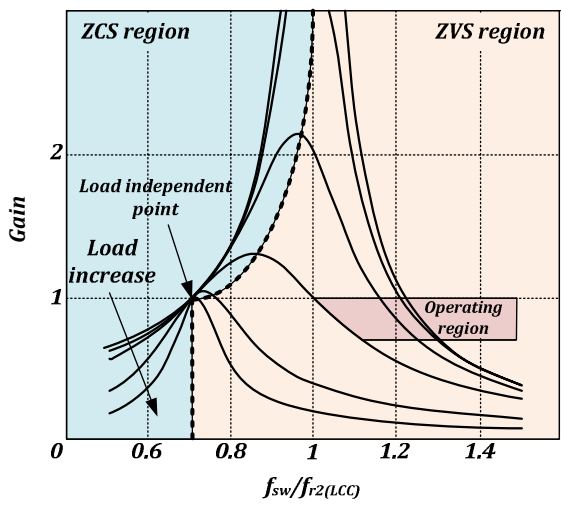

(b)

Fig. 3. Generalised voltage gain vs. normalised frequency at different loads for LLC converter (a) and LCC converter (b)

$$
\begin{gathered}
f_{r 1(L L C)}=\frac{1}{2 \cdot \pi \sqrt{L_{r} \cdot C_{r}}}, \\
f_{r 2(L L C)}=\frac{1}{2 \cdot \pi \sqrt{\left(L_{r}+L_{p}\right) \cdot C_{r}}} .
\end{gathered}
$$

Since the load independent point (higher resonant frequency) is in the ZVS region (Fig. 3a), the converter could be designed to operate around this point $[10,11]$. High efficiency is achievable by applying lossless capacitive snubbers across the inverter transistors.

The LLC converter does not require an LC output filter used in traditional hardswitching HB converter. Only the capacitor filter can be used, leading to a simpler and lighter secondary part. The required capacitance value is estimated by

$$
C_{f}=\frac{1}{4 \cdot \Delta U_{\text {out }} \cdot f_{\text {sw(min })} \cdot R_{\text {Load (min })}},
$$

where $\Delta U_{\text {out }}$ is the output voltage ripple, $f_{s w(\min )}$ is the minimum switching frequency, and $R_{\text {Load(min })}$ is the minimum equivalent load resistance.

\section{LCC Resonant Converter}

The series-parallel converter, also referred to as an LCC converter, aims at combining the advantages of the series and the parallel converters, at the same time reducing or eliminating their disadvantages. Similarly to the LLC, the LCC converter does not require an LC output filter used in a traditional hard-switching $\mathrm{HB}$ converter. The transformer leakage inductance can be utilised as the resonant element $L_{r}$. 
The low resonant frequency is determined by a series resonant tank $L_{r}$ and $C_{r}$ while the high resonant frequency is determined by $L_{r}$ and an equivalent capacitance of $C_{r}$ and $C_{p}$ in series. Two resonant frequencies, $f_{r l(L C C)}$ and $f_{r 2(L C C)}$ are defined as follows [12]

$$
\begin{gathered}
f_{r 1(L C C)}=\frac{1}{2 \cdot \pi \sqrt{L_{r} \cdot C_{r}}}, \\
f_{r 2(L C C)}=\frac{1}{2 \cdot \pi \sqrt{\frac{L_{r} \cdot C_{p} \cdot C_{r}}{C_{p}+C_{r}}}} .
\end{gathered}
$$

The behaviour is dependent on the $C_{r} / C_{p}$ ratio. As $C_{p}$ is reduced, the converter resembles a series converter and the upper frequency needed at light loads increases. On the other hand, with an increased $C_{p}$ the converter resembles a parallel converter and the circulating current no longer decreases with the load [8].

Unlike in the case of the LLC converter, the load independent point (lower resonant frequency) is in the ZCS region, while in the ZVS region (the higher resonant frequency) the converter is more sensitive to changes in the load (Fig. 3b). Only the operation above the upper resonance will be considered in the following as it is more desirable from the practical point of view since the ZVS is provided for the IGBTs, allowing the use of capacitive snubbers to reduce turn-off losses.

\section{Simulation Results and Loss Comparison}

Design of resonant components is always a compromise between load power range, operating frequency, input voltage range, circulating energy in the resonant circuit etc.

From the efficiency point of view the LLC converter is best to be operated at the resonant frequency $f_{r I(L L C)}$. In this case the both circulating energy in the resonant network as well as the switching losses are low. Since this operating point is only achievable for one given $U_{i n}$ and load power, the LLC resonant converter is usually designed around $f_{r l(L L C)}$ for a full load and maximum $U_{i n}$. With an increase in the load or a decrease in the input voltage, the switching frequency is decreased to keep the output voltage regulated.

Similarly, the LCC converter is usually designed around $f_{r 2(L C C)}$ for a full load and minimum $U_{i n}$. The step-by-step analysis and design methods of LLC and LLC converters were presented in a range of publications [8-13] and are beyond the scope of this paper.

The values of the resonant tank components of both converters are selected so that their switching frequency range is similar and relatively narrow $(3 \ldots 4 \mathrm{kHz})$ and the isolation transformer turns ratio is the same. The main parameters of the analysed converters are listed in Table 1. The input voltage and load power range as well as the output voltage values are the same as for the hard-switched converter. Both converters are able to operate with ZVS within desired conditions. The simulated waveforms of LLC and LCC converters operating at nominal conditions are shown in Figs. 4a and $4 b$, respectively. Simulations show that the turn-off current of IGBT as well as peak current of the rectifier diodes is essentially higher in the LCC converter (Fig. 5). 
Table 1. Main parameters of the compared converters

\begin{tabular}{|c|c|c|c|c|c|c|c|c|}
\hline Converter & $\begin{array}{c}\text { Switching } \\
\text { frequency } \\
\left(f_{s w}, \mathrm{kHz}\right)\end{array}$ & $\begin{array}{c}\text { Transformer } \\
\text { turns ratio } \\
\left(N_{s} / N_{p}\right)\end{array}$ & $\begin{array}{c}C_{r} \\
(\mu \mathrm{F})\end{array}$ & $\begin{array}{c}C_{p} \\
(\mu \mathrm{F})\end{array}$ & $\begin{array}{c}L_{r} \\
(\mathrm{mH})\end{array}$ & $\begin{array}{c}L_{p} \\
(\mathrm{mH})\end{array}$ & $\begin{array}{c}L_{f} \\
(\mathrm{mH})\end{array}$ & $\begin{array}{c}C_{f} \\
(\mathrm{mF})\end{array}$ \\
\hline Hard-switched & 2 & 0.4 & - & - & - & - & 5 & 0.74 \\
\hline LLC & $2.9 \ldots 3.9$ & 0.17 & 1.2 & - & 1.32 & 2.64 & - & 2.4 \\
\hline LCC & $3.0 \ldots 3.9$ & 0.17 & 2.2 & 1.8 & 2.87 & - & - & 2.4 \\
\hline
\end{tabular}

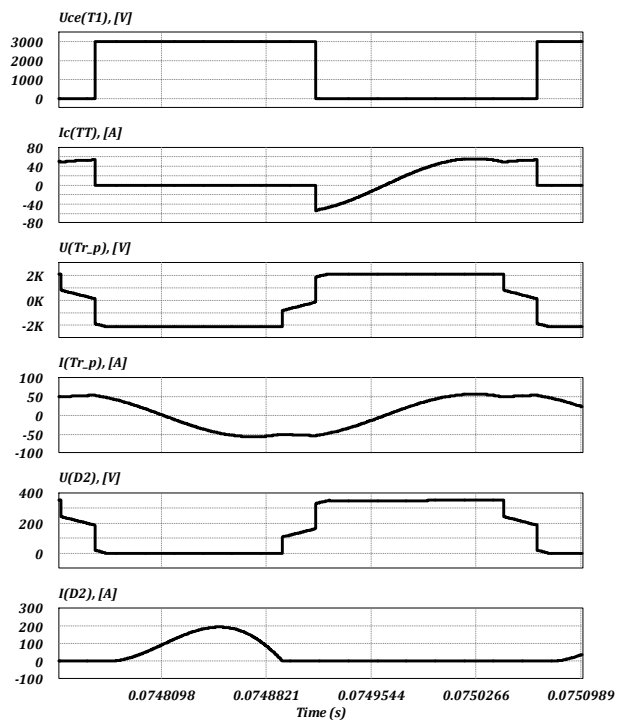

(a)

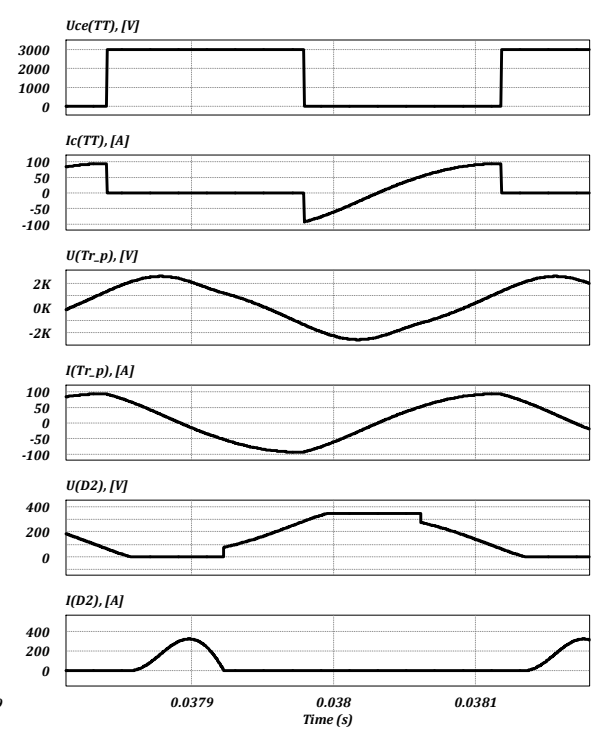

(b)

Fig. 4. Main simulation waveforms of LLC (a) and LCC (b) converters $\left(U_{i n}=3000 \mathrm{~V}\right.$, $\left.P_{\text {out }}=30 \mathrm{~kW}\right)$

The estimated inverter IGBT power loss in the studied solutions is presented in Fig. 6. The simulations of LLC and LCC converters include the IGBT loss reduction during the turn-off with the snubber capacitors. Since reductions in the IGBT turn-off power loss by help of capacitive snubbers have been reported to be lower than expected due to increased current tail duration and could vary between different IGBTs, the approximate average reduction of 50\% [14-17] is considered in this paper. It should be mentioned that in real converters, the power losses could be distinctly higher than the simulated values due to additional power dissipation of passive components and the output rectifier.

Despite operating with higher switching frequency than the hard-switched converter, the resonant LLC converter is able to provide essential (up to $57 \%$ ) reduction of inverter losses. On the contrary, the power losses of the LCC converter are higher, especially at higher input voltages. This situation could be improved by adjusting $C_{r} / C_{p}$ ratio. As a downside, the operation frequency range will increase. 


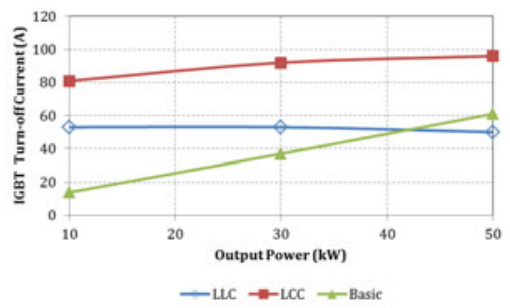

Fig. 5. IGBT turn-off current vs. load power of the considered converters $\left(U_{i n}=3000 \mathrm{~V}\right)$

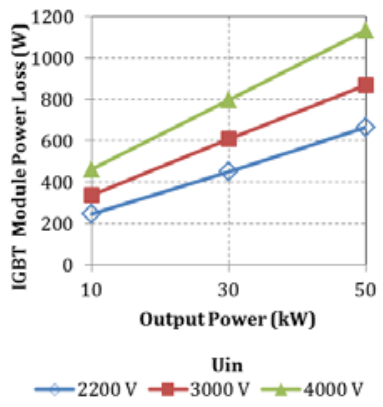

(a)

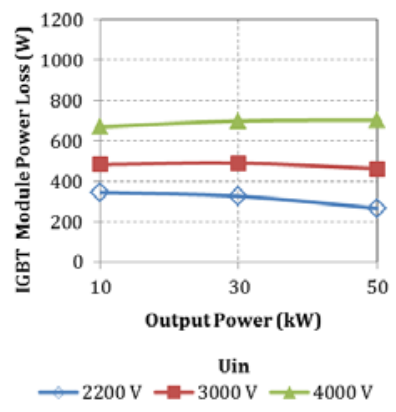

(b)

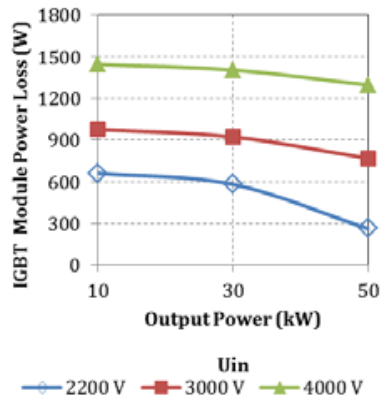

(c)

Fig. 6. Single IGBT module power loss estimation vs. output power at different input voltages in hard-switched (a), LLC (b) and LCC (c) converters

\section{Conclusions}

Implementation of resonant converters instead of the hard switching half-bridge topologies seems to be an attractive way of improving the efficiency of the power converter. Both LLC and LCC converters can deliver low noise and ZVS of the inverter switches over the whole range of operation conditions. From the two, the LCC converter design requires additional adjustments in order to reduce switching losses. This will result in a wider regulation frequency range, making design more challenging. On the contrary, the LLC converter performance seems advantageous due to lower power losses with a similar regulation frequency range. On the other hand, the additional complexity of the topology, its control and protection as well as possible reduction in robustness reliability may not overcome the advantages it brings. The further research will focus on investigations of HB topology with phaseshifted synchronous rectifier, which seems an advantageous alternative since it does not require any modifications in the inverter part.

Acknowledgement. This research work has been supported by Estonian Ministry of Education and Research (Project SF0140016s11), Estonian Science Foundation (Grant ETF8020) and Estonian Archimedes Foundation (project - „Doctoral School of Energy and Geotechnology II“). 


\section{References}

1. Jalakas, T., Vinnikov, D., Laugis, J.: Development of 50-kW Isolated DC/DC Converter with High-Voltage IGBTs. In: Compatibility in Power Electronics, CPE 2007, pp. 1-6 (2007)

2. Blinov, A., Jalakas, T., Vinnikov, D., Janson, K.: Switch-Off Behaviour of 6.5 kV IGBT Modules in Two-Level Voltage Source Inverter. Scientific Journal of Riga Technical University: Power and Electrical Engineering 27, 121-126 (2010)

3. Aydemir, M.T., Evran, F.: Operation principles of a switched capacitor snubber circuit suggested for half-bridge DC-DC converters. International Journal of Electronics 96(1), 29-42 (2009)

4. Coccia, A., Canales, F., Riniker, H.R., Knapp, G., Kalbermatten, M., Baldinger, M., Barbosa, P.: Very high performance AC/DC/DC converter architecture for traction power supplies. In: 13th European Conference on Power Electronics and Applications, EPE 2009, pp. 1-11, 8-10 (2009)

5. Lin, B.R., Hou, B.R.: Implementation of a series resonant converter with series-parallel connection. In: 6th IEEE Conference on Industrial Electronics and Applications (ICIEA), pp. 1179-1184 (2011)

6. Lindenmuller, L., Alvarez, R., Kleinichen, P., Bernet, S.: Characterization of a $6.5 \mathrm{kV} /$ 500A IGBT module in a series resonant converter. In: Energy Conversion Congress and Exposition (ECCE), pp. 4138-4143. IEEE (2011)

7. Weigel, J., Ag, A.N.S., Hoffmann, H.: High voltage IGBTs in medium frequency traction power supply. In: 13th European Conference on Power Electronics and Applications, EPE 2009, pp. 1-10 (2009)

8. Batarseh, I., Liu, R., Ortiz-Conde, A., Yacoub, A., Siri, K.: Steady state analysis and performance characteristics of the LLC-type parallel resonant converter. In: 25th Annual IEEE Power Electronics Specialists Conference, PESC 1994 Record, vol. 1, pp. 597-606 (1994)

9. Yang, B., Lee, F.C., Zhang, A.J., Guisong, H.: LLC resonant converter for front end DC/DC conversion. In: Seventeenth Annual IEEE Applied Power Electronics Conference and Exposition, APEC 2002, vol. 2, pp. 1108-1112 (2002)

10. Cavalcante, F.S.: High Output Voltage Series-Parallel Resonant DC-DC Converter for Medical X-Ray Imaging Applications, D.Sc. thesis, pp. 26-38 (2006)

11. LLC resonant half-bridge converter design guideline, STMicroelectronics Application note AN2450 (October 2007)

12. Steigerwald, R.L.: A Comparison of Half-bridge resonant converter topologies. IEEE Transactions on Power Electronics 3(2) (1988)

13. Jung, J.H., Kwon, J.G.: Theoretical analysis and optimal design of LLC resonant converter. In: 2007 European Conference on Power Electronics and Applications, pp. 1-10 (2007)

14. Naayagi, R.T., Shuttleworth, R., Forsyth, A.J.: Investigating the effect of snubber capacitor on high power IGBT turn-off. In: 2011 1st International Conference on Electrical Energy Systems (ICEES), pp. 50-55 (2011)

15. Fujii, K., Koellensperger, P., De Doncker, R.W.: Characterization and Comparison of High Blocking Voltage IGBTs and IEGTs Under Hard- and Soft-Switching Conditions. IEEE Transactions on Power Electronics 23(1), 172-179 (2008)

16. Song, B.M., Zhu, H., Lai, J.H., Hefner, A.R.: Switching characteristics of NPT- and PTIGBTs under zero-voltage switching conditions. In: Thirty-Fourth IAS Annual Meeting. Conference Record of the 1999 IEEE Industry Applications Conference, vol. 1, pp. 722728 (1999)

17. Petterteig, A., Lode, J., Undeland, T.M.: IGBT turn-off losses for hard switching and with capacitive snubbers. In: Conference Record of the 1991 IEEE Industry Applications Society Annual Meeting, vol. 2, pp. 1501-1507 (1991) 